\title{
A retrospective evaluation of haematological values in clinical cases of water buffaloes
}

Nittin D. Singh, Harmanjit S. Banga, Prashant D. Gadhave, Madhav N. Mugale

College of Veterinary Science

Guru Angad Dev Veterinary and Animal Science University, Ludhiana - Punjab, India

Corresponding author: Nittin D. Singh, email:drndsingh@gmail.com

Received: 25-05-2012, Accepted: 04-07-2012, Published online: 01-12-2012

\section{How to cite this article:}

Singh ND, Banga HS, Gadhave PD and Mugale MN (2013) A retrospective evaluation of haematological values in clinical cases of water buffaloes, Vet World 6(2): 103-105. doi: 10.5455/vetworld.2013.103-105

\begin{abstract}
Aim: To evaluate the important haematological values of the retrospective clinical cases of buffaloes presented to the Teaching Veterinary Hospital of the College of Veterinary Science, Guru Angad Dev Veterinary and Animal Science University, Ludhiana over a period of 4 years from January 2007 to December 2010.

Materials and methods: The blood was collected from jugular vein in EDTA containing vials. Statistical analysis of haematological values with different case history/clinical signs was performed using SPSS 16.0 version by applying one way ANOVA at $\mathrm{P}<0.05$. Clinical pathology of these cases was monitored by comparing hemogram values with the reference range.

Results: The most common disorders found in water buffaloes were digestive disorders followed by fever and respiratory disorders. Haematological values viz. TLC, DLC (neutrophil, lymphocyte and eosinophil counts) showed significant differences depending upon the case history/clinical signs while haemoglobin count was found to be statistically nonsignificant.
\end{abstract}

Conclusion: TLC and DLC are found to be the important indicators of health status of water buffaloes in general which are more related to clinical history/clinical signs of this species than other the haematological parameters viz. haemoglobin count.

Key words: case history, clinical signs, haematological values.

\section{I ntroduction}

Hematologic values are useful in determining the general health status of the animal [1] besides, it helps to differentially diagnose disease conditions, severity of disease and monitor response to therapy. In general the complete blood count (CBC) is performed to assess the general health status. It consists of parameters related to erythrocyte, leukocyte and platelets viz. red blood cell count (TEC), packed cell volume (PCV), hemoglobin concentration ( $\mathrm{Hb})$, mean corpuscular volume (MCV), mean corpuscular hemoglobin (MCH), mean corpuscular hemoglobin concentration (MCHC), white blood cell (TLC) and differential leukocytic count (DLC). Amongst them Hb, TLC and DLC are routinely performed haematological parameters. The important diagnostic information can be obtained by comparing the $\mathrm{CBC}$ values with clinical signs/ history [2]. There has been lot of discussion on the effect of season on these parameters in healthy ruminants and different disease conditions in controlled environment $[3,4]$.

However, there is scarcity of information on buffaloes and their actual comparison of haematological values of different clinical cases and their clinical signs/case history. Similarly it is not always possible to perform all the CBC values in every case due to lack of facilities, time constrains and economic conditions.
Therefore the present study was carried out to compare clinical signs/case history with laboratory findings of important haematological parameters which play significant role in diagnosis and resultantly treatment regimens in clinical cases presented.

\section{Materials and Methods}

The blood samples of buffaloes along with clinical signs/history received over a period of 4 years from January 2007 to December 2010 at the Pathology unit of the Clinical Diagnostic Laboratory of College of Veterinary Science, Guru Angad Dev Veterinary and Animal Science University, Ludhiana were part of this study. All these samples were collected from the jugular vein in (10\%) ethylenediaminetetraacetic acid (EDTA) containing vials. The blood portal was done as per the standard protocols of [5]. The collected data was analysed by using SPSS 16.0 version by applying one way ANOVA at $\mathrm{P}<0.05$.

\section{Results and Discussion}

A total of 1025 haematological reports of clinical cases of buffaloes were analyzed. These cases were then classified into different categories depending upon the clinical signs and history of cases involved and problems reported such as nervous signs (4.09\%), urinary disorders $(3.06 \%)$, cardiovascular disorders $(0.78 \%)$, digestive disorders $(36.87 \%)$, cases of fever of unknown origin $(25.46 \%)$, integumentary disorders 
Table-1. Statistical analysis and reference haematological values for the buffalo

\begin{tabular}{|c|c|c|c|c|c|c|c|c|}
\hline Clinical signs/history & $\mathbf{N}$ & $\begin{array}{l}\mathrm{Hb}(\mathrm{g} / \mathrm{dl}) \\
(9-13.5) \\
\text { Mean } \pm \text { S.E. }\end{array}$ & $\begin{array}{l}\text { TLC }\left(\text { cells } / \mathrm{mm}^{3}\right) \\
(6250-13050) \\
\text { Mean } \pm \text { S.E. }\end{array}$ & $\begin{array}{l}\text { Reference Ran } \\
\text { N (\%) } \\
(13-54) \\
\text { Mean } \pm \text { S.E. }\end{array}$ & $\begin{array}{l}\text { e } \\
\text { L(\%) } \\
(26-75) \\
\text { Mean } \pm \text { S.E. }\end{array}$ & $\begin{array}{l}E(\%) \\
(1-11.5) \\
\text { Mean } \pm \text { S.E. }\end{array}$ & $\begin{array}{l}M(\%) \\
(2-14) \\
\text { Mean } \pm \text { S.E. }\end{array}$ & $\begin{array}{l}\text { B }(\%) \\
(0-3) \\
\text { Mean } \pm \text { S.E. }\end{array}$ \\
\hline Nervous signs & 42 & $10.63 \pm 0.33$ & $10684.52^{\mathrm{ad}} \pm 636.58$ & $63.26 \pm 2.36$ & $35.55 \pm 2.41$ & $0.93^{\mathrm{a}} \pm 0.43$ & $0.24 \pm 0.1$ & $0.00 \pm 0.00$ \\
\hline Urinary diseases & 37 & $10.54 \pm 0.37$ & $11741.35^{\mathrm{ab}} \pm 698.9$ & $66.27^{\mathrm{ac}} \pm 2.78$ & $32.3^{\mathrm{ad}} \pm 2.59$ & $0.81^{b} \pm 0.21$ & $0.41 \pm 0.15$ & $0.00 \pm 0.00$ \\
\hline Foreign body syndrome & 8 & $11.38 \pm 0.63$ & $7056.25 \pm 794.37$ & $74.5 \pm 1.64$ & $24.5^{\mathrm{b}} \pm 1.92$ & $0.5^{\mathrm{c}} \pm 0.33$ & $0.25 \pm 0.25$ & $0.00 \pm 0.00$ \\
\hline Digestive disorders & 378 & $10.7 \pm 0.11$ & $11488.04^{\mathrm{abc}} \pm 354.67$ & $65.5^{\text {bdf }} \pm 0.76$ & $32.76^{\mathrm{cf}} \pm 0.7$ & $0.76^{d} \pm 0.08$ & $0.53 \pm 0.07$ & $0.00 \pm 0.00$ \\
\hline $\begin{array}{l}\text { Fever } \\
\text { Disorders of integumentary } \\
\text { system }\end{array}$ & $\begin{array}{l}261 \\
17\end{array}$ & $\begin{array}{l}10.68 \pm 0.13 \\
10.84 \pm 0.42\end{array}$ & $\begin{array}{l}13673.6^{\mathrm{c}} \pm 449.48 \\
11051.18 \pm 844.22\end{array}$ & $\begin{array}{l}56.07^{\mathrm{ab}} \pm 1.13 \\
60.82 \pm 4.74\end{array}$ & $\begin{array}{l}42.09^{\mathrm{ac}} \pm 1.08 \\
35.88 \pm 4.37\end{array}$ & $\begin{array}{l}0.81^{\mathrm{e}} \pm 0.1 \\
1.18 \pm 0.78\end{array}$ & $\begin{array}{l}0.5 \pm 0.07 \\
0.94 \pm 0.59\end{array}$ & $\begin{array}{l}0.03 \pm 0.02 \\
0.00 \pm 0.00\end{array}$ \\
\hline Musculoskeletal disorders & 10 & $11.42 \pm 0.51$ & $11780 \pm 957.09$ & $63.5 \pm 2.51$ & $36.4 \pm 2.51$ & $0^{9} \pm 0$ & $0.1 \pm 0.1$ & $0.00 \pm 0.00$ \\
\hline Nutritional problems & 26 & $9.74 \pm 0.34$ & $11761.15 \pm 849.1$ & $63.54 \pm 2.61$ & $33.96 \pm 2.57$ & $2.36^{\text {cde }} \pm 1.07$ & $0.23 \pm 0.12$ & $0.00 \pm 0.00$ \\
\hline Parasitic infestations & 15 & $11.19 \pm 0.75$ & $18491.33^{\text {bcd }} \pm 7310.06$ & $58.27 \pm 3.66$ & $37.93 \pm 3.9$ & $3.27^{\mathrm{a}-\mathrm{i}} \pm 1.77$ & $0.4 \pm 0.29$ & $0.13 \pm 0.13$ \\
\hline Reproductive system disorders & 58 & $10.65 \pm 0.29$ & $11410.17 \pm 616.17$ & $63.66^{\mathrm{e}} \pm 2.25$ & $34.91^{\mathrm{e}} \pm 2.1$ & $0.53^{h} \pm 0.21$ & $0.16 \pm 0.06$ & $0.00 \pm 0.00$ \\
\hline $\begin{array}{l}\text { Respiratory disorders } \\
\text { Tumors }\end{array}$ & $\begin{array}{l}115 \\
5\end{array}$ & $\begin{array}{l}10.71 \pm 0.2 \\
9.4 \pm 0.72\end{array}$ & $\begin{array}{l}14013.74 \pm 621.14 \\
8990 \pm 1573.32\end{array}$ & $\begin{array}{l}59.21^{\mathrm{f}} \pm 1.62 \\
58.8 \pm 3.5\end{array}$ & $\begin{array}{l}39.35^{\mathrm{cf}} \pm 1.58 \\
40 \pm 3.58\end{array}$ & $\begin{array}{l}1.03^{i} \pm 0.19 \\
1.2 \pm 0.8\end{array}$ & $\begin{array}{l}0.69 \pm 0.18 \\
0 \pm 0\end{array}$ & $\begin{array}{l}0.06 \pm 0.04 \\
0.00 \pm 0.00\end{array}$ \\
\hline Miscellaneous disorders & 53 & $10.95 \pm 0.35$ & $15544.53^{\mathrm{a}} \pm 1264.07$ & $52.96^{\text {cde }} \pm 2.72$ & $45.58^{\text {bcde }} \pm 2.75$ & $1.08^{f} \pm 0.29$ & $0.34 \pm 0.12$ & $0.00 \pm 0.00$ \\
\hline Total & 1025 & $10.69 \pm 0.07$ & $12567.74 \pm 235.82$ & $61.36 \pm 0.53$ & $36.92 \pm 0.51$ & $0.89 \pm 0.07$ & $0.48 \pm 0.04$ & $0.02 \pm 0.01$ \\
\hline
\end{tabular}

Hb- Haemoglobin, TLC- Total leucocytes count, N- Neutrophil, L- Leucocyte, E- Eosinophil, M- Monocyte, B- Basophils Means bearing same superscript in a row differ significantly $(p<0.05)$ with clinical signs/history.

$(1.65 \%)$, respiratory signs $(11.21 \%)$, musculoskeletal disorders $(0.97 \%)$, cases suspected for tumour $(0.48 \%)$, parasitic infestations (1.45\%), nutritional disorders $(2.53 \%)$, reproductive disorders $(5.65 \%)$ and miscellaneous disorders (5.17\%). The important haematological parameters of these cases such as haemoglobin, total leukocyte count and differential leukocyte count were studied. The data was analyzed by using statistical analysis software programme SPSS 16.0. The results of statistical analysis and reference haematological values for the buffalo [6] are given in table-1.

The haemoglobin level in all the cases did not vary significantly with the type of disorder but average haemoglobin level of all these cases was found to be on lower side of the reference value. Similar findings were also reported by [7] who observed non significant differences between haemoglobin values of diseased cattle. The lower haemoglobin values could be correlated with mild increase in positive acute phase proteins in blood which are iron binding protein, especially hepatoglobin whose level significantly increase in different inflammatory conditions [8].

The range of mean haemoglobin level in different clinical cases varied from $(10.7 \pm 0.11 \mathrm{~g} / \mathrm{dl})$ in cases with history of digestive disorders to $(11.42 \pm 0.51 \mathrm{~g} / \mathrm{dl})$ in buffaloes with musculoskeletal problems. Lower $\mathrm{Hb}$ levels might be due to the decreased absorption of the haemoglobin precursors in digestive disorders viz. diarrhoea, enteritis etc. Similarly in tumour cases, average $\mathrm{Hb}$ level $(9.4 \pm 0.72 \mathrm{~g} / \mathrm{dl})$ was found towards lower side of the reference range which might be due to the blood loss at the site of the neoplasia and replacement of erythropoetic tissue. Remaining diseased conditions did not showed great variation in the haemoglobin level.

The total leukocytic count, neutrophil, lymphocyte and eosinophil count varied significantly with clinical signs and history while monocyte and basophil count were statistically non significant. The overall total leukocyte count was found to be increased (12567.74 \pm 235.82 cells/cu mm). In the present study, leukocytosis was observed in parasitic diseases, miscellaneous disorders, respiratory disorders and in fever. The most common parasitic infestations in these buffaloes was found to be anaplasmosis, babesiosis and hook worm infestations when correlated with the reports from the parasitology unit. Similar findings were also recorded by [9]. The respiratory disorders most commonly observed during this study were pneumonia and hemorrhagic septicaemia. Fever was found to be one of the most common manifestations in observed clinical cases accompanied by the leukocytosis. The total leukocyte count found to be increased probably due to various physiologic responses besides infections or inflammatory changes going on in these animals. Stressful conditions can increase cardiac output and blood pressure resulting in to leukocytosis. Stress along with infections and inflammations leads to alterations in immunity which may play role in increased incidence and severity of respiratory diseases. Similarly other studies also observed neutrophilic leukocytosis $[10,11]$ in stressful conditions.

The highest neutrophil count was observed in cases suspected for cardiovascular disorders (74.5 $\pm 1.64 \%)$ and urinary disorders $(66.27 \pm 2.78 \%)$ while cases with history of miscellaneous disorders (52.96 $\pm 2.72 \%$ ) did not show significant increase in neutrophil count. Cardiovascular disorders in these buffaloes were mostly related with foreign body syndrome which is one of the most common syndromes in buffaloes because of their indiscriminate feeding habits [12]. The findings of higher neutrophilic count were correlated with the inflammatory responses like bacterial infection, abomasal displacement, necrosis, uremia, toxicosis etc. in these cases. Concurrent observations were reported by [13] and [14] who reported physiological responses like fear, excitement and exercise result in neutrophilia besides bacterial infection, necrosis, neoplasia etc. Interestingly, in the present study none of the category of disorders showed neutropenia or absolute lymphopenia. The highest eosinophil count above average was found in cases with history of parasitic infestation which is well 
known feature of this type of disorder $[13,14]$. Musculoskeletal disorders in buffaloes did not reveal presence of eosinophils during the differential count of leukocytes.

Increase in monocyte count was reported to be important finding during chronic inflammations [13] such as tuberculosis [14]. Also concurrent eosinophilia and basophilia was sometimes observed chronic respiratory diseases [5]. However, monocyte and basophil count were found to be nonsignificant during this study.

The comparison of history, clinical signs, disease incidence, etc with the laboratory data could be helpful for final diagnosis [4]. But it is difficult to evaluate them under field conditions. Some of these parameters like $\mathrm{Hb}$, TLC and DLC are easy to perform and gives important information on health status. The present study reported that haematological values viz. TLC, DLC (neutrophil, lymphocyte and eosinophil counts) of clinical cases and their variation with clinical signs/history was statistically significant while haemoglobin level, monocyte and basophil count were found to be non significant.

\section{Conclusion}

TLC and DLC are found to be the important indicators of health status of water buffaloes in general which are more related to clinical history/clinical signs of this species than other the haematological parameters viz. haemoglobin count.

\section{Author's contribution}

NDS and HSB participated in the preparation of experimental design and facilities of the research. PDG and MNM collected and analysed the data. NDS, HSB, PDG and MNM drafted and revised the manuscript. All authors read and approved the final manuscript.

\section{Acknowledgements}

Authors are thankful to the head of Teaching Veterinary Clinical Complex for providing the necessary facilities.

\section{Competing interests}

Authors declare that they have no competing interests.

\section{References}

1. Beechler B.R., Jolles A.E. and Ezenwa V.O. (2009). Evaluation of hematologic values in free-ranging African buffalo (Syncerus caffer), J. Wildlife Dis., 45(1): 57-66.

2. Weiss D.J. and Wardrop K.J., editors. (2010). Schalm's Veterinary Hematology, 6th edition. Blackwell Publishing Ltd., Iowa, USA.

3. Kumar B. and Pachaura S.P. (2000). Haematological profile of crossbred dairy cattle to monitor herd health status at medium elevation in central Himalayas, Res. Vet. Sci., 69:141-145.

4. Aengwanich W., Chantiratikul A. and Pamok S. (2009). Effect of Seasonal Variations on Hematological Values and Health Monitor of Crossbred Beef Cattle at Slaughterhouse in Northeastern Part of Thailand, American-Eurasian J. Agric. \& Environ. Sci., 5(5): 644-648.

5. Benjamin M.M. (2007). Outline of Veterinary Clinical Pathology, 3rd edition. Kalyani publishers, Ludhiana, New Delhi.

6. Wills T.B. (2010). Hematology of water Buffalo (Bubalia bubalis). In Schalm's Veterinary Hematology, 6th edition. Weiss D.J. and Wardrop K.J., editors. Blackwell Publishing Ltd., Iowa, USA. 928-929.

7. Alsaad K.M. (2011). Evaluation of hemogram, hepatoglobine and chronic factors indices in cattle affected with acute and chronic peritonitis, J. Anim. Vet. Adv., 10(1) 11-17.

8. Skinner J.G., Brown R.A. and Roberts L. (1991). Bovine haptoglobin response in clinically defined field conditions, Vet. Rec., 128:147-149.

9. Ananda K.J., Placid E., D'Souza and Puttalakshmamma G.C. (2009). Prevalence of Haemoprotozoan diseases in crossbred cattle in Bangalore north, Vet. World, 2(1):15-16.

10. Blecha F and Baker P.E. (1986). Effect of cortisol in vitro and in vivo on production of bovine interleukin 2, Am J Vet Res., 47:841-845.

11. Murata H., Takahashi H. and Matsumoto H. (1987). The effect of road transportation on peripheral blood lymphocyte subpopulations, lymphocyte blastogenesis and neutrophil function in calves, Br. Vet. J., 143:166-174.

12. Singh J., Singh A.P. and Patil D.B. (1993). The Digestive System. In: Ruminal Surgery, Tyagi R.P.S. and Singh J., editors. CBS. Publishers and Distributors, Delhi.183-224.

13. Davidson M., Else R. and Lumsden J. (1998). BSAVA Manual of Small Animal Clinical Pathology. British Small Animal Veterinary Association, Cheltenham UK. 33-60.

14. Spivak J.L. (1984). Fundamentals of Clinical Hematology. Harper \& Row, Publishers, Inc., Pennsylvania. 123-134. 